\title{
Can depression be prevented?
}

\author{
JAN ScotT, Senior Lecturer in Community \\ Psychiatry, University of Newcastle \\ upon Tyne
}

Prevention is traditionally a controversial issue in psychiatry. Many would consider it to have no empirical base and therefore regard the whole idea as unscientific. However, doctors cannot evade their obligations to consider exploring important issues of public health simply because the methodology is complex. The Social, Community and Rehabilitation Psychiatry Section of the Royal College has struggled with the issue of prevention over a number of years. The deliberations of an earlier working party within the Section chaired by Dr C. M. Parkes and the conclusions of more recent meetings convened by $\mathrm{Dr}$ A. C. Brown perhaps yielded more questions than they have been able to answer. Thus, in an attempt to widen the debate within the College it was decided to devote the entire February 1989 Annual General meeting of the Section to this somewhat neglected topic. The meeting focused on the role of prevention with particular reference to its application to depressive disorders. Depression provides an interesting model to examine in this context as it spans the spectrum of neurosis to psychosis and many different aetiological theories have been proposed.

The morning session (chaired by Dr D. G. Fowlie, Aberdeen) was devoted to a discussion of some of these theories and the possibilities for primary prevention. Dr Nicol Ferrier (MRC, Newcastle) examined the functioning of the hypothalamicpituitary-adrenal (HPA) axis and tried to offer some links between biological and cognitive models of depression. Professor McGuffin (Cardiff) suggested that the propensity to encounter adversity and (genetic) vulnerability to depression cluster in certain families. Professor George Brown (Bedford College) addressed the social origins of depressive disorders and discussed prevention in schematic terms. Using this model he identified four possible intervention points (preventing crises; avoiding background diffculties; preventing developmental problems; and 'post-onset' interventions). Lastly, Dr Jennifer Newton (a prevention research worker with MIND) outlined some examples of good practice in prevention, e.g. NEWPIN. She then contrasted disease models with health promotion approaches and suggested that in order to set up and evaluate interventions based on the former, research needed to be focused on vulnerable groups. It might then be possible to identify the types of support that were likely to be effective in preventing depression despite the presence of risk factors. The talk also highlighted the need to mobilise voluntary, community and natural support networks as well as the use of innovative primary and secondary care processes to promote prevention.

The latter half of the day (chaired by Professor E. S. Paykel, Cambridge), covered secondary and tertiary prevention. Dr Ian Falloon and colleagues (from Buckingham) outlined a service model that offered early intervention to depressed patients and their families by the placement of mental health professionals in primary care settings. The efficacy of cognitive therapy in the treatment of depression was then discussed by Dr Jan Scott (Newcastle). Finally Dr Abou-Saleh (Liverpool) systematically outlined pharmacological approaches to depression.

What did we learn from the day? In the plenary session (led by Professor E. S. Paykel) it was suggested that overall we could feel more confident about our knowledge and ability to treat depressive disorders, but early intervention required early detection. There was a need to train and help other professionals in this area. More importantly, he pointed out that the crux of the matter was whether or not there were any good examples within psychiatry of primary prevention. It is certainly time for such approaches to be tried; depressed patients, their families, and the public at large now expect it from us. The early addresses had outlined the need for clinicians to utilise multifactorial models of depression. Given the heterogeneity of this disorder, how confident are we at predicting the risk of developing depression? (Thus allowing us to target a vulnerable population as suggested by Dr Newton).

A wide ranging discussion with the audience highlighted concerns that the models of depression put forward were not as robust as we would like. It is important that future research tries to integrate psychobiosocial approaches rather than set up competing aetiological theories. The fundamental question of the role of a psychiatrist in primary prevention remains unresolved. Perhaps, by necessity, a one day meeting posed more new questions rather than identifying solutions. At the end, Professor Paykel asked a question of those present - if you were given the task of advising the health minister on how to spend $10 \%$ of the available resources on primary prevention for the treatment of depression what would you suggest? Most of the attenders at the meeting probably mused on how to tackle this question on the train going home. If they have now come up with the answers, could they please let us know! 